\title{
Theories of Social Systems: Implications for Health Care System
}

\author{
Angella Vassell ${ }^{1} \&$ Tuyen D. Nguyen ${ }^{2}$ \\ ${ }^{1}$ Human Services Department, Walden University, Minneapolis, USA \\ ${ }^{2}$ Human Services Department, California State University, Fullerton, USA \\ Correspondence: Tuyen D. Nguyen, Human Services Department, California State University, Fullerton, CA, \\ 92834, USA. Tel: 1-657-278-5695. E-mail: Trunguyen@fullerton.edu
}

\author{
Received: January 16, 2012 \\ Accepted: January 31, $2012 \quad$ Published: June 1, 2012 \\ doi:10.5539/ijps.v4n2p273 \\ URL: http://dx.doi.org/10.5539/ijps.v4n2p273
}

\begin{abstract}
The health care system has begun to focus on providing more effective treatment to war veterans and promoting collaboration between state, federal, and private agencies. In this paper the authors will provide historical perspectives on the health care system and synthesize themes related to the theories of Ludwig von Bertalanffy (1968), Niklas Luhmann (1982), and Anthony Gidden (1984).
\end{abstract}

Keywords: health care system, applied theories, health care management system

\section{Introduction}

The first introduction of General System Theory (GST) as a new paradigm was introduced by Bertalanffy (1968). Briefly, health care shares certain characteristic that allow them to function as systems, the system can be any type or level of organization (Bertalanffy, 1968). This introduction may have forced health care organization, to figure out complex organizational structures in apparent disregard of the dynamics. While the health care systems continue to struggle to provide quality care, there, is room for improvement. As previously stated, our health care system is in need of help, and a change is needed within the environments. Then along came inequality and health care disparities. It can be argued that these disparities added many disagreements in health care quality. The use of services and treatment are also affected. Health care disparities have resulted in costly health care services (Bertalanffy, 1968). With the inconsistence in health care practices there have been many cases of missed diagnoses, which always result in complications for the patients that receive care.

For many decades, delivery of health care services has been poor and continues to worsen (Plsek, 2001). The consideration of a person health and providing quality care is no longer a priority. Instead, it is more focused on monetary gain verses quality. When a solider/veteran goes for treatment they expect to receive quality care. A need for a new way of thinking was needed in order to bring about changes in the services health care providers rendered.

\subsection{The Shift in Paradigm}

In recent years, a need to improve the way humanity is surviving has become the main concern of the systems community (Plsek, 2001). The current shift is occurring due to new technology, changes and experiences. Even with the positive changes that can be brought about, they tend to be a disruption to current practices, theories and arrangements already in place. The major areas that suffer are quality of care. Some of the factors that attribute to this are many services are not being utilized and not many have access to health care services provided. The use of services refer to the barriers that may delay one from seeking care, which often result in illness that is now in the later stages. The access to health care is an important part of accessing and obtaining quality care (Plsek, 2001). Some of the barriers to accessing health care can be attributed to race and ethnicity, no insurance and one's socioeconomic position.

In the recent years politicians reported that they intend to cut the federal budget by $\$ 400$ billion (Plsek, 2001). This cut will have a greatly affect the health care and disability benefits of many veterans. They proposed that this will reduce the compensation of disability benefits to account for their social security payments. With the continuation, of two wars in effect and thousands of troops needing continuous medical care how will this change affect the future care of our soldiers. If the changes should take place, many of our veterans/soldiers will receive no care or inadequate care. The need for health care services for our veterans should be the top priority of the Veterans Administration (VA) and the politicians who make changes to the laws (Plsek, 2001). With so many 
of our soldiers returning with multiple diagnoses, it is critical to receive health care services and benefits. For many soldiers returning from the war, this issue at hand should be a top priority to ensure their well-being. If they were able to change this it would leave many disappointed in the system that they trust to protect them. The questions that arise from this story in respect to social systems are the types of communication the VA has with the law makers? Also, why so many soldiers put their trust in a system that care so little about their well-being? These are the research objectives that this paper's authors would like to address.

\section{Historical Development and Evolution of Social Systems}

\subsection{The Organizational Perspective}

The objective for this section is to analyze the organizational development and paradigm theory of Niklas Luhmann (1968). More specifically, this section intended to examine how management structure operates in order to produce quality care in a manner that allows the VA health systems to continue serving our soldiers and veterans with the quality care they need.

Luhmannn (1968) also was a soldier in the military. During his time of service in World War II, he was captured by the enemies and became a prisoner of war. The main focus of Luhmann's theory of social systems is communication. Nicklas Luhmanns (1968) theory does not view an organization as a group, nor as a single individual, but instead it was viewed as a social system. For Luhmann, social systems were viewed and classed as a closed network of communication. Luhmann viewed communication as the irreducible final element of an 'emergent event' (Luhmann 1984).

Each system can be distinctively identity and reproduced communication that can be considered a negative or positive thought (Sociology-Niklas Luhmann. (n.d). Retrieved from http://www.about sociology.com/sociology/Niklas_Luhmann). If a system fails to maintain its identity, it cannot function, as a system and it will return back into the environment from which it came. According to Luhmann (1984), the organization is not classed as individuals acting as a group nor an individual actor, but instead a social system. These new levels of information create different constructs to meet necessary roadblock needed to address specific issues within Luhmann's theory. To this Luhmann stated that, theories provide a comprehensive account of system, the general principles which apply comprehensively to subsystems including the economy and science as a social system.

In more general terms, organizations learn to communicate through various subsystems. That is systems cannot observe themselves from the outside. As such, organizations must develop the ability to be observed by others in order to access and improve their environment. This linked to the advancement in the development of sociology. In a sequential manner, the normal stage that follows is self-referential; this was accomplished to function on its own. From there, there are developments in the observation of others. The observer observation relays heavily on the observers' situation, verses what is being observed. From the information, given above resulted in communication that forms from new levels of information processing. Yet, the act of communication can be related to a specific part and not necessarily the whole. In collusion Luhmann (1984) stated that, "various societal systems were constructed to conduct the communication within the various systems" (p.85).

From Luhmann's (1979) communication evolution evolves a paradigm on human consciousness that can be examined by relating the paradigm to speech. Speech is the result of a basic medium of communication. "Speech is a sound often misconstrued and falsified, because of its improbability, due to its descriptions and statements receive great consideration (Lee, p. 110)". This is a direct result of a new construct of information that is responding to a demand or need. What Luhmann's (1979) paradigm present was a shift in how it was believed that speech was affected in communication? Furthermore, Luhmann contended that "communication is the only genuinely social phenomenon".

Thus, in Luhmann thought the direction of evolution results from a variation, selection, and restabilization, within the realm of communication. This evolution for Luhmann is the construct of autopoieses. So what about Luhmann's paradigm on autopoieses? Autopoiesis allow a system to establish a barrier within its environment. The system then produces its own structures and entities. "Autopoieses are not produced from other structures Gestalt). The differences between the systems and their environment are critically important to the structure" (p. 66). A social system becomes apparent when the communication process begins and result in autopoieses, it will develop within itself. "Communication becomes autopoietic when it is intertwined with other communication, within a network produced by that specific communication" (Luhmann, 1982, p. 3). While operations are performed the structural coupling increase and becomes complicated. Social, Temporal, and Functional dimensions allows communication to flow. Self-description occurs in order to be classed as a unit, allowing it to be known or unknown. Self-description is constructed of self-reflective narrative, an "autological" information 
that is distinctive within that dimension.

Autopoiesis of Society

Communication

Social

$$
\text { Evolution }
$$

*

Temporal

$*$

Self-description of Society
Differentiation

Functional

Figure 1. Luhmann's result of his thinking

\subsection{The Speech Perspective}

Luhmann(1984) suggested that speech possesses its unique form. This arrangement is constructed of two opposing sides that evolve from the difference between sound (Laut) and meaning (Sinn) (Lee, 2007). As previously stated, communication was used to transmit information. In theorizing so, Luhmann implicates that speech allows one to communicate original thoughts and ideas (Luhmann, p. 213). This is the paradigm in Luhmann's theory as previous scholarly thought believed that when speech was communicated it is highly "improbable" even that most of the time, results in some degree of misunderstanding.

\section{Structuration Theory and Framework}

There is a lack of health care organizations practicing structuration theory to probe deeper into the problems within. The need to explore professionalism and self-awareness have been utilized by Kondrat (1999) as a new way of thinking, Structuration theory was also utilized by Fergusion (2001) who explored practice and theory used in community based organizations. Giddens (1998) paved the way and foundation in the United States and Britain on welfare reform.

\subsection{Structuration}

Giddens (1984) developed Structuration Theory as a way to combine agency structure into a sociological theory. This theory will allow hope for all organizations that was considered of all dimensions. Structuration theory suggests that the representation of consciousness-raising can have a broad impact on empowerment practice. The main concern of structuration is the way social structures affect our consciousness and behavior that was displayed (Marx, 1964). Structuration has been implemented to increase the impact of empowerment practices.

Giddens (1984) believed that social structure have been intended to provide restricted explanations of human agency, while theorist of organizations was inattentive to structural arrangement and development. After reviewing the limitations of both, he developed the Structuration theory to exhibit the relationship between social structures and human beings. The Structuration process of social relations is often referred to as "Social Practices". When human agency and social structure intertwine, this will give them the opportunity to produce different interventions Giddens (1984).

\subsection{Consciousness- Raising Perspective}

In many organizations, they congregate jointly to discuss a way to make improvements and how they can incorporate the changes and learn from them. This process was referred to as Consciousness raising. When you have the ability to confront your oppression, the transformation process from the acted- upon object to an acting subject who can"...perceive the cause of reality" (p. 131). First, this society had Giddens asking himself, how aware are we of our daily activities that create and recreate social structures? Second, how aware are we of how social structures and social arrangements influence our consciousness and behaviors? Giddens replied to these questions, by stating that we have been made up of three types of consciousness and knowledge that organize our experience and the interpretation of everything around us. The type of knowledge includes, Mutual Knowledge, Practical Knowledge, and Discursive Knowledge. Mutual Knowledge is the highest level. This knowledge gives you the ability to retain day to day information given to members of a community. It is "the knowledge that we must possess in order to understand what we are doing and what others do to affect our social lives" (Giddens, 1987, p. 65). This knowledge allows social practices to function together. Practical Knowledge was assumed or 
accepted by the receiver with no regards unless it was challenged. This allows the receiver to challenge those assumptions and examine the information that has been received. This form of knowledge can be addressed in discussion "what you were allowed to verbalize or to express feelings towards conditions, especially conditions related to our own actions" (Giddens, 1984, p. 374). Discursive knowledge entails, being aware of our actions and being able to describe why we chose to engage in them. This knowledge is what we know or believe, especially our own conditions that cannot be expressed discursively (Giddens, 1984).

\section{Implications for Structuration Practice}

Structuration Theory provides consciousness-raising which brings about empowerment practices (Giddens, 1984). This theory will provide an understanding of organization, while it allows individuals to be knowledgeable and empowered, which will allow them to make positive changes to their social structures based on their actions. Such understandings will innate quality care practices. This will address the structural and health care practices of the veterans' lives as well as the behavior we display when interacting with then. The implication will allow an organization to make changes that will produce positive social practices.

\subsection{Applying Structuration Theory to Critical Consciousness in Health Care Practices}

Applying structuration theory to critical consciousness practices in health care practices, is that individuals must want to bring change to that social relationship. Giddens (1984) argued that before social practices can be transformed, they must be dispassionately examined so that all parties' performances may be understood. To bring any positive change, it has to be understood that the participants can benefit from the social practice, thus lessening any discomfort; for example, many soldiers who participated in combat in "Afghanistan". They are among thousands of troops who are experiencing Post-Traumatic Stress Disorder or PTSD after returning from the current wars. Many of the soldier's well-being was compromised. Many of these soldiers were faced with psychological trauma, and mental health issues and many are not receiving quality care needed to return to society (civilian life). Due to the lack of care many soldiers are not treated and priority was given to physically wounded soldiers. It is "however", relative to understanding that this diagnosis is very relevant to the array of soldiers returning from the countless wars. For these soldiers and many veterans, the flashbacks, trauma, sleeplessness nights, and visits to a psychiatrist office await these soldiers after many was diagnosed with post-traumatic stress disorder they are afraid to release the information to their command. This diagnosis leaves them feeling trapped, suicidal, frustrated, and detached. The health care providers would need to provide quality care to the individuals.

It would be in the soldier best interest to work collaboratively with the health care providers (Giddens, 1984). The provider can also assist in order to provide the care needed to bring stability and a sense of normalcy. Building a new relationship with health care providers after a traumatic episode is difficult in the process of change. At this point, many soldiers have difficulty initiating this process and usually find the support and treatment to be very helpful.

The practice of consciousness-raising describes earlier emphasized the importance of working jointly to provide support. Many organizations may benefit from initiating change in their social practices. This will make it easier more for an individual to engage and make positive changes.

\section{Conclusion}

This paper has attempted to analyze, discuss, and shed some light on how social systems have impacted how organizations interact with their social structure. In doing so, evolution development was analyzed from the historical, theoretical, organizational, and structuration perspective. In addition, three theorists on social systems were reviewed both in theory as well as, in a compare and contrast aspect. Finally, there was a brief discussion centered on how the theories analyzed viewed the link between theoretical constructs and paradigms. It is how the focus of this discourse to take the broad information given and apply to an example in order to further understands the impact of social systems in health care systems. To do so, there will be a connection between the theories given and the various concepts introduced in the beginning, a brief discussion on the possible implication of the connection, and an analysis of what could occur.

In looking at the systems interaction with its environment example, from Bertalanffy, (1968) standpoint it is argued that systems and the environment are separate boundaries. After all if, changes are needed in an organization, the process starts and ends with the administrator's approval.

On the other hand, how does communication play into social systems? According to Luhmann (1984) social systems develop as a direct rest when the communication process begins and results in autopoeses (Luhmann, 1982). In stating so, it may be that speech allows one to communicate original thoughts and ideas. Yet, what if 
the relationship between communication and speech was the cause of misunderstandings? Giddens contended that the Structuration process develops the representation of consciousness-raising can have a broad impact on practice, particularly, for the need to link the relationship between social structure and human beings. This link may lead to a better understanding of how social systems, especially in developing organizational structures as part of society.

\section{References}

Bertalanffy, L. V. (1968). General system theory: Foundations, development, applications. London: Allen Lane.

Ferguson, L. (2001). Structuration theory and critical consciousness: Potential applications for social work practice. Journal of Sociology \& Social Welfare, 36, 123-140.

Giddens, A. (1984). The constitution of society. Berkeley: The University of California Press.

Giddens, A. (1987). Social theory and modern sociology. Palo Alto: Stanford University Press.

Giddens, A. (1998). The Third Way: The Renewal of Social Democracy. United Kingdom: Polity.

Kondrat, T. (1999). Sociology and the new systems theory: Toward a theoretical synthesis. Albany, NY: SUNY Press.

Lee, O. (2007). Making sense of the organization. Oxford, UK: Blackwell Publishing.

Luhmann, N. (1982). The autopoiesis of social systems. In Geyer F, Van der Zouwen J (Eds.), Socio cybernetic Paradoxes (pp. 172-192). London: Sage.

Luhmann, N. (1984). Soziale Systeme. Grundriß einer allgemeinen Theorie. Frankfurt a. M.: Suhrkamp.

Marx, K. (1964). Economic and Philosophic Manuscripts of 1844. New York City, International Publishers

Plsek, T. (2001). The Blackwell companion to social theory. Malden, Mass: Blackwell Publishers. 